\title{
On restart of automated manufacturing systems using restart states*
}

\author{
Patrik Bergagård and Martin Fabian
}

\section{EXTENDED ABSTRACT}

Highly automated manufacturing systems have gained industrial popularity for their ability to combine high product volumes with high product quality. The high cost of investment in combination with many linked manufacturing systems in a factory, requires that the production runs smoothly with high utilization of the resources and that stoppages are avoided. One major reason for stoppages is the occurrence of errors. A wide variety of possible faults, such as badly fixated parts, broken actuators, and teething problems in the system, may cause errors that lead to an unsynchronization between the control system and the physical system that consequently lead to production stoppages $[1,2]$. The succeeding error recovery is often a complex and thereby time consuming process that typically requires operator involvement [3]. To plan for restart after errors already during the development of the system would therefore greatly support the online restart process and reduce the time the production is undesirably stopped. The common industrial practice to deal with such non-intended progress is to extend the control system with tailor-made solutions to account for foreseen errors [4,5]. This extension is both time consuming and there is no guarantee that all relevant errors are handled.

\section{A. Restart using precalculated restart states}

In this presentation we will present how automatically calculated restart states can support both offline and online work with restart of the production. These restart states are states in the control system from where it is correct to resynchronize the control and the physical systems so that the production can be resumed, irrespectively if the error is foreseen or unforeseen. The calculation of restart states is based on solving a supervisory control theory problem [6]. The method aids during the development of the system by letting the developer focus on modeling the nominal production and on specifying (un-)desired behavior during the restarted production, and then automatically retrieve the correct restart states for all control states. The production can thus be designed for restart. Based on these precalculated

* This work has been carried out at the Wingquist Laboratory VINN Excellence Centre within the Production Area of Advance at Chalmers. It has been supported by VIRTCOM-Virtual preparation and commissioning of production systems including PLC logics, reference number 2014-01408, Vinnova, FFI within Sustainable production technology. The support is gratefully acknowledged.

Patrik Bergagård is with the Automation research group at the Department of Signals and Systems, Chalmers University of Technology, Sweden. (phone: +46 31-1786772; e-mail: patrikm@ chalmers.se).

Martin Fabian is with the Automation research group at the Department of Signals and Systems, Chalmers University of Technology, Sweden. (email: fabian@chalmers.se). restart states, the online restart process is reduced to a semiautomatic process where an operator can be supported with instructions for how to correctly resynchronize the control and the physical systems in a selected restart state.

\section{B. Validation of the proposed restart method}

The proposed restart method has been validated on an industrial station for automatic mounting of windscreens onto car bodies [7]. The station is shown in Figure 1. The restart states are calculated for demonstration. The expressiveness of the model is sufficient to capture the required alternative product routing in the station and to express the desired requirements on the restarted production. By studying historical production stoppages for the windscreen mounting station, it can be concluded that if the proposed restart method had been used, using restart states calculated from the developed model, the restart after unforeseen errors that caused long production stoppages could have been improved. This presentation will elaborate on how the station was modeled and exemplify how restart states supports an operator if the station needs to be restarted.

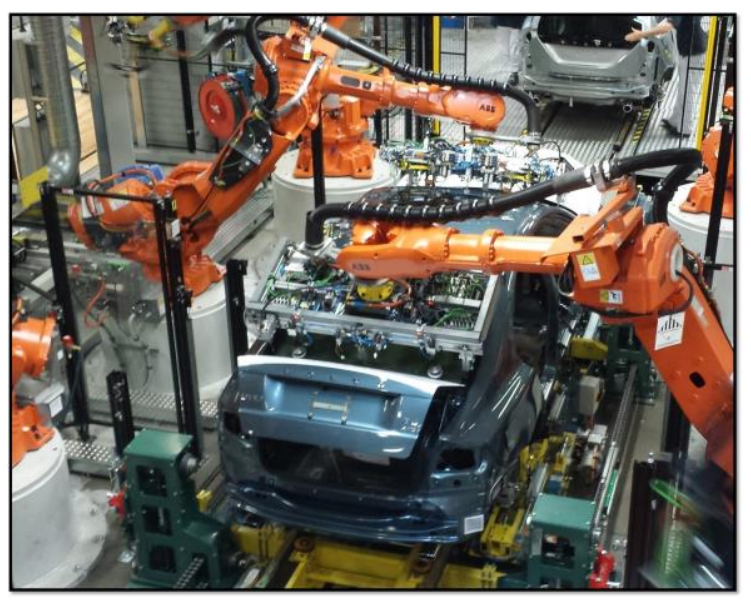

Figure 1. The windscreen mounting station.

\section{REFERENCES}

[1] M. C. Zhou and F. Dicesare, "Adaptive design of Petri net controllers for error recovery in automated manufacturing systems," IEEE Trans. Syst. Man Cybern., vol. 19, no. 5, pp. 963-973, 1989.

[2] N. G. Odrey and G. Mejia, "An augmented Petri Net approach for error recovery in manufacturing systems control," Robot. Comput. Integr. Manuf., vol. 21, no. 4-5, pp. 346-354, 2005.

[3] K. Andersson, B. Lennartson, P. Falkman, and M. Fabian, "Generation of restart states for manufacturing cell controllers," Control Eng. Pract., vol. 19, no. 9, pp. 1014-1022, 2011.

[4] N. Lagergren, Control system developer at Teamster. Personal communication, 2014. 
[5] C. Augustsson, Senior Project Leader at Volvo Car Corporation. Personal communication, 2014.

[6] P. Bergagård and M. Fabian, "Calculating Restart States for Systems Modeled by Operations Using Supervisory Control Theory," Machines, vol. 1, no. 3, pp. 116-141, 2013.

[7] P. Bergagård, P. Falkman, and M. Fabian, "Modeling and automatic calculation of restart states for an industrial windscreen mounting station," in IFAC Symposium on Information Control in Manufacturing, 2015. 